\title{
Editorial
}

\section{A fresh look at oncology facts on south central Asia and SAARC countries}

WHO divides the world into several regions. ${ }^{[1]}$ One of them is South Central Asia. This consists of 14 countries Islamic republic of Iran, 5 that were born from the former USSR (Kazakhstan, Kyrgyzstan, Tajikistan, Turkmenistan, and Uzbekistan), and remaining 8 that are together called the SAARC countries (Afghanistan, Bangladesh, Bhutan, India, Maldives, Nepal, Pakistan, and Sri Lanka). The population of South Central Asia and SAARC Countries forms $26.68 \%$ and $24.59 \%$ of the world population, respectively [Table 1]. ${ }^{[2-4]}$ As far as cancer in these regions is concerned, incidence of new cases is $11.24 \%$ and 10.23 $\%$ of the world's cases. Yet, the burden of cancer deaths as compared to the incidence is $68.85 \%$ and $68.44 \%$, respectively. This compares poorly to the $59.74 \%$ for the world. This well-known fact reaffirms that these regions of the world need to improve their cancer management strategies.

Facts about cancer in South Central Asia are shown in Table 2. For the entire population, the 5 most common cancers are cancer of cervix and uterus, breast cancer, lung cancer, oral cancer and Cancer of esophagus. ${ }^{[2,3]}$ Interestingly, the 5-year prevalence of cancers is significantly higher in females.

The Southern countries of Asia (India, Pakistan, Nepal, Bangladesh, Bhutan, Sri Lanka, Afghanistan, Maldives, Burma, and Tibet) share more than just a common love of chai, cricket, and Bollywood. We also share a matching oncologic profile, albeit with some regional differences. With respect to figures for South Central Asia, the SAARC countries contribute a burden of $91.10 \%$ of incidence, $90.93 \% 5$-year prevalence and $90.56 \%$ of cancer deaths [Tables 1, 3]. Hence, importance of focusing on oncology in SAARC countries cannot be over-emphasized.

As an overview, in males, lung and oral cancer rank as the top 2 prevalent cancers while in women, breast, and cervical cancer take the top 2 spots. ${ }^{[5]}$ Let us now take the

\begin{tabular}{|l|l|}
\hline \multicolumn{2}{|c|}{ Access this article online } \\
\hline Quick Response Code: & Website: \\
\hline & www.sajc.org \\
\hline & \\
\hline
\end{tabular}

SAARC nations of India, Pakistan, Bangladesh, Bhutan, Nepal, and Sri Lanka that are coming together for this manuscript. For instance, the level of oncologic care varies widely across our countries as well as within each country. The number of trained oncologists varies from a high of 1500 in India to a low of 2 in Bhutan [Table 4].

We will also consider the 6 countries individually in terms of cancer burden and the level of oncologic expertise available.

Starting with India, there are 27 dedicated cancer hospitals and an additional 300 general or multispecialty hospitals that provide care to cancer patients. There are about 1 million patients diagnosed with cancer each year with the majority being diagnosed in an advanced stage, leading to a significant number of deaths. Cancer is the $4^{\text {th }}$ leading cause of death in India in the 25 to 69 year age group, ranking behind cardiovascular disease, respiratory disease, and tuberculosis. There are 1500 trained oncologists who take care of these patients, compared to a total number of over 4.4 lakh doctors of all specialties. India has an official national cancer control program, that mainly focuses on primary, secondary and tertiary cancer prevention strategies, a national cancer registry program, 5 oncology societies, 300 radiotherapy machines, produces 5 cancer journals and organizes at least 55 oncology-centric conferences annually. Although this may seem like a situation of plenty, in actuality, this is not the case. There are over 1 billion people in India, of which there are about 24 lakh persons with cancer at any given point of time according to the WHO report. Thus, the ratio of cancer patients to oncologists in India is 1600 to 1 . Compare this to the results of a study commissioned by ASCO in 2008 that predicted that by the year 2020, there will be 12,500 oncologists in America available to care for the nearly 1.4 million Americans diagnosed with cancer each year, leading to a ratio of about 100 patients to 1 oncologist. ${ }^{[5,6]}$ The same ASCO report actually raised concerns over the growing shortage in the oncologist workforce, in spite of this seemingly enviable ratio! Their analysis projected an increase of $14 \%$ in oncology training seats, whereas the demand for patients requiring oncology visits was expected to increase by $48 \%$. This was mainly due to the growth and aging of the population as well as the increase in the number of cancer survivors. Yet, only $30 \%$ expected that the government shall fund new positions 
to increase training capacity, and in fact as many as $24 \%$ did not know where such funding might be forthcoming. As a result, the training program directors at oncology centers in USA were of the opinion that there will not be a significant increase in the number of oncology training positions during the next 5 years. In the light of the current limitations (financial, administrative, and others) in India (and other SAARC countries), we can expect that our preparedness for the future, at best, is woefully inadequate.
The oncology situation in the other SAARC countries is roughly comparable to that in India in terms of cancer patients to doctors. However, due to the smaller population and smaller actual numbers of oncologists, all types and level of oncology specialists may not be available. For example, there are 2 qualified oncologists in Bhutan, both of whom are surgeons. Thus, there is no trained medical oncologist in Bhutan, and no radiotherapy machines in a country with a population of 7.25 lakhs. Bhutan had 639

Table 1: Comparison of population, cancer incidence, cancer deaths, and cancer prevalence rates in different regions

\begin{tabular}{|c|c|c|c|c|c|}
\hline & Population & $\begin{array}{c}\text { New cancer cases / } \\
\text { year }\end{array}$ & $\begin{array}{c}\text { Cancer deaths / } \\
\text { year }\end{array}$ & $\begin{array}{c}5 \text { year cancer } \\
\text { prevalence (adults) }\end{array}$ & $\begin{array}{l}\text { Cancer prevalence } \\
\text { as proportion per } \\
\mathbf{1 0 0 , 0 0 0} \text { population }\end{array}$ \\
\hline World & $6,750,062,000$ & $12,662,554$ & $7,564,802$ & $28,803,200$ & 585.8 \\
\hline South Central Asia & $1,728,752,000$ & $1,423,200$ & 979,900 & $2,682,400$ & 228.7 \\
\hline SAARC countries & $1,659,700,000$ & $1,296,558$ & 887,355 & $2,439,285$ & \\
\hline India & $1,247,300,000$ & 948,858 & 633,455 & $1,705,085$ & 211.4 \\
\hline Pakistan & $176,900,000$ & 139,200 & 101,600 & 304,000 & 274.0 \\
\hline Bangladesh & $150,700,000$ & 141,100 & 103,300 & 291,200 & 267.8 \\
\hline Afghanistan & $32,400,000$ & 14,400 & 11,400 & 27,500 & 188.3 \\
\hline Nepal & $30,500,000$ & 27,800 & 20,000 & 56,100 & 310.3 \\
\hline Sri Lanka & $20,900,000$ & 24,400 & 17,000 & 53,700 & 353.3 \\
\hline Bhutan & 700,000 & 600 & 500 & 1,100 & 243.1 \\
\hline Maldives & 300,000 & 200 & 100 & 600 & 260.9 \\
\hline
\end{tabular}

Table 2: Cancer facts in south central Asia

\begin{tabular}{|c|c|c|c|}
\hline South-central Asia & Male & Female & Both sexes \\
\hline Population (thousands) & 888237 & 840515 & 1728752 \\
\hline Number of new cancer cases (thousands) & 651.2 & 772.0 & 1423.2 \\
\hline Age-standardised rate $(\mathrm{W})$ & 99.8 & 110.8 & 104.6 \\
\hline Risk of getting cancer before age $75(\%)$ & 10.9 & 11.4 & 11.1 \\
\hline Number of cancer deaths (thousands) & 496.8 & 483.1 & 979.9 \\
\hline Age-standardised rate (W) & 78.0 & 71.7 & 74.4 \\
\hline Risk of dying from cancer before age $75(\%)$ & 8.7 & 7.8 & 8.2 \\
\hline 5-year prevalent cases, adult population (thousands) & 993.8 & 1688.6 & 2682.4 \\
\hline Proportion (per 100,000) & 165.6 & 294.8 & 228.7 \\
\hline \multirow[t]{5}{*}{5 most frequent cancers (ranking defined by total number of cases) } & Lung & Cervix uteri & Cervix uteri \\
\hline & Lip, oral cavity & Breast & Breast \\
\hline & Other pharynx & Ovary & Lung \\
\hline & Oesophagus & Lip, oral cavity & Lip, oral cavity \\
\hline & Stomach & Oesophagus & Oesophagus \\
\hline
\end{tabular}

Table 3: Incidence and deaths of cancer in SAARC countries

\begin{tabular}{|c|c|c|c|c|c|c|c|}
\hline & $\begin{array}{c}\text { SAARC } \\
\text { Countries }\end{array}$ & India & Pakistan & Bangladesh & Nepal & $\begin{array}{c}\text { Sri } \\
\text { Lanka } \\
\end{array}$ & Bhutan \\
\hline New cancer cases / year & $1,296,558$ & 948,858 & 139,200 & 141,100 & 27,800 & 24,400 & 600 \\
\hline$\%$ among SAARC & & $73.18 \%$ & $10.73 \%$ & $10.88 \%$ & $2.14 \%$ & $1.88 \%$ & $0.05 \%$ \\
\hline Cancer deaths / year & 887,355 & 633,455 & 101,600 & 103,300 & 20,000 & 17,000 & 500 \\
\hline$\%$ among SAARC & & $71.39 \%$ & $11.45 \%$ & $11.64 \%$ & $2.25 \%$ & $1.92 \%$ & $0.06 \%$ \\
\hline Death as $\%$ of incidence within country & & $66.76 \%$ & $72.99 \%$ & $73.21 \%$ & $71.94 \%$ & $69.67 \%$ & $80 \%$ \\
\hline
\end{tabular}


Table 4: Insight into oncology status of SAARC Countries

\begin{tabular}{|c|c|c|c|c|c|c|}
\hline Question & Bhutan & Pakistan & India & Bangladesh & Sri Lanka & Nepal \\
\hline Number of qualified oncologists in the country & 2 & 125 & 1500 & 150 & 18 & 40 \\
\hline Number of cancer centers in the country & 1 & 20 & 27 & 18 & 06 & 5 \\
\hline $\begin{array}{l}\text { Number of other hospitals treating cancer patients } \\
\text { in the country }\end{array}$ & 1 & 50 & 300 & 30 & 04 & 5 \\
\hline $\begin{array}{l}\text { Number of new cancer patients diagnosed every } \\
\text { year in the country }\end{array}$ & 300 & 150,000 & $1,000,000$ & 100,000 & 15,000 & 30,000 \\
\hline $\begin{array}{l}\text { Number of medical oncology journals brought out } \\
\text { by the country }\end{array}$ & Nil & 0 & 5 & 3 & None & None \\
\hline $\begin{array}{l}\text { Number of oncology conferences and CMEs } \\
\text { conducted in the country every year }\end{array}$ & $\begin{array}{l}\text { Only once in } \\
2011\end{array}$ & 6 & 55 & 20 & 05 & 30 \\
\hline $\begin{array}{l}\text { Number of radiotherapy machines currently } \\
\text { available in working condition in the country }\end{array}$ & Nil & 25 & 300 & 19 & 11 & 6 \\
\hline $\begin{array}{l}\text { Number of scientific societies/ associations } \\
\text { dedicated to oncology in the country }\end{array}$ & $\begin{array}{l}\text { Nil now, } \\
\text { going to set } \\
\text { up soon }\end{array}$ & 2 & 5 & 3 & 01 & 10 \\
\hline $\begin{array}{l}\text { Is there degree training in oncology (any branch) } \\
\text { available in the country }\end{array}$ & No & Yes & Yes & Yes & Yes & Yes \\
\hline $\begin{array}{l}\text { Is there an official national healthcare policy for } \\
\text { cancer in the country (of any nature) }\end{array}$ & Yes & No & Yes & No & Yes & Yes \\
\hline
\end{tabular}

cancer patients registered in the year 2010. If requiring oncologic surgeries, especially gynecologic oncological surgeries, patients are able to benefit from treatment within Bhutan. However, the majority, needing radiotherapy or chemotherapy currently, have to make their way to India for management. Recently, the Jigme Dorji Wangchuck National Referral Hospital (JDWNRH) established a chemotherapy unit, taking into account the increasing number of cancer patients noted in the country (albeit at the expense of abandoning plans for a new burns unit). Ongoing initiatives to prevent cancer include pap smear program and HPV vaccination for the whole country, hepatitis $\mathrm{B}$ vaccination for all newborns and a nationwide ban on sale of tobacco - truly commendable activities.

Pakistan, with its population of over 173 million people, is the $6^{\text {th }}$ most populous country in the world. There are over 1.4 million cancer patients in Pakistan, and approximately 150,000 new cancer patients are added each year. There are 20 cancer hospitals and 50 other hospitals where cancer patients can be cared for. There are 125 trained oncologists, 25 radiotherapy machines, 6 oncology-centric conferences, and provision for specialized oncology training in Pakistan. Pakistan recently established the Karachi Cancer Registry and the Pakistan Cancer Control Program 2. ${ }^{[7]}$ However, Pakistan has yet to publish an oncology journal.

Bangladesh, at 142 million people, is the $9^{\text {th }}$ most populous country in the world. There are 13 to 15 lakh cancer patients in Bangladesh, with about 2 lakh patients newlydiagnosed with cancer each year. In order to care for these patients, there are 150 qualified oncologists, 18 cancer hospitals and an additional 50 general hospitals that accept and provide care to cancer patients. Bangladesh publishes
3 oncology journals, organizes 20 oncology conferences annually, has 3 oncology societies, an oncology training program, and several hospital-based and population-based cancer registries. Therefore, oncology specialty is relatively well-established in Bangladesh, but there is no national cancer program yet.

Nepal, with its population of almost 30 million, has about 30,000 new cancer patients each year. These patients can receive oncologic care from 40 trained oncologists in 5 cancer centers. There is provision for radiotherapy, postgraduate oncology training programs, and a national cancer policy. Nepal also does not publish an oncology journal.

Sri Lanka, with a population of 20 million, also has a wellestablished oncologic program. There are approximately 15,000 new patients diagnosed with cancer in Sri Lanka annually. There are 6 cancer hospitals and 18 qualified oncologists. Radiation therapy is relatively easily available with 11 radiation therapy machines in the country, including a recently commissioned linear accelerator at the National Cancer Center, Maharagama, Colombo.

There is a $3^{\text {rd }}$ issue that remains an important factor in this region. So far, we have discussed global figures (Globocan, IARC, WHO, etc) and opinions of experts in the SAARC countries [Table 4]. What about data from local registries that show that Globocan data is underestimating cancer incidence in our countries? Let us take the example of breast cancer in India. The Indian Council of Medical Research population-based cancer registry of New Delhi shows the incidence to be 29.3 per 100,000 of the population in 1994-95. ${ }^{[8,9]}$ And, the Indian 
Cancer Society's Maharashtra population-based registry shows it to be 26.8 per 100,000 of the population in $2001 .{ }^{[9,10]}$ Both these figures are higher than the $<19.5$ incidence per 100,000 population showed in Globocan 2002 data. $^{[11]}$

Thus, the infrastructure and human resources for oncologic care in South Asia is steadily improving. However, we have a long way to go. By providing a forum to share clinical observations, educational material, research findings, and news of conferences and meetings, we hope that the SAJC will provide an impetus to accelerate advances in cancer care for South Asia and ultimately help us provide the best care possible to the quarter of the world's population that has made this region their home.

\section{Vanita Noronha, Ugyen Tsomo', Arif Jamshed', MA Hai ${ }^{3}$, Sarath Wattegama ${ }^{4}$, RP Baral ${ }^{5}$, Madan Piya $^{6}$,} Kumar Prabhash

Department of Medical Oncology, Tata Memorial Hospital, Mumbai, India,' 'Department of Gynaecology Oncology, Jigme Dorji Wangchuk National Referral Hospital, Thimpu, Bhutan, ${ }^{2}$ Department of Radiation Oncology, Shaukhat Khanum Memorial Cancer Hospital and Research Centre, Lahore, Pakistan, ${ }^{3}$ Director, Bangladesh Cancer Hospital and Welfare Home, Dhaka, Bangladesh, ${ }^{4}$ Department of Clinical Oncology, Lakeside Adventist Hospital, Kandy, Sri Lanka, ${ }^{5}$ Department of Medical Oncology, B\&B Hospital, Lalitpur, Nepal, ${ }^{6}$ Chairman and Director, National Cancer Hospital, Lalitpur, Nepal

Correspondence to: Dr. Vanita Noronha, E-mail: vanita.noronha@gmail.com

\section{References}

1. Jemal A, Bray F, Center MM, Ferlay J, Ward E, Forman D. Global Cancer Statistics. Ca Cancer J Clin 2011;61:69-90.

2. Cancer Worldwide, Sept 2011. Available from: http://publications. cancerresearchuk.org/publicationformat/formatstats / statsworldwide20051.html. [Last cited in 2012].

3. GLOBOCAN 2008 v. 1.2. Cancer Incidence and Mortality Worldwide IARC 2010. Available from: http:/globocan.iarc.fr. [Last cited in $2011 \mathrm{Feb}]$.

4. PRBs world population datasheet 2011. The world at 7 Billion: A PRB Interactive Map. Available from: http://www.prb.org. [Last cited in 2012].

5. Moore MA, Ariyaratne Y, Badar F, Bhurgri Y, Datta K, Mathew A, et al. Cancer epidemiology in South Asia - past, present and future. Asian Pac J Cancer Prev 2010;11 Suppl 2:49-66.

6. Erikson C, Schulman S, Kosty M, Hanley A. Oncology Workforce: Results of the ASCO 2007 Program Directors Survey. J Oncol Pract 2009;5:62-4.

7. Bhurgri Y. Karachi Cancer Registry Data--implications for the National Cancer Control Program of Pakistan. Asian Pac J Cancer Prev 2004;5:77-82.

8. Raina V, Tyagi B, Manoharan N. Population based cancer registry Delhi. Available from: http://www.icmr.nic.in/ncrp/report pop_2001-04/05_Delhi\%20Pages\%20154-173.pdf. [Last cited in 2012].

9. Nandakumar A, Ramnath T, Roselind F, Shobaba B, Prabhu K. Two year report of the population based cancer registries 1999-2000. Available from: http://www.icmr.nic.in/ncrp/1999-00/PBCR\%20 Report\%201999_00.pdf. [Last cited in 2012].

10. Kurkure AP, Yoele B, Koyande S. Cancer incidence and mortality in greater Mumbai 2006. Available from: http://www. indiancancersociety.org/cancer-resgistry/cancer-registry.htm. [Last cited in 2012].

11. Parkin M, Bray, Ferlay J, Pisani P. Global Cancer Statistics, 2002. CA Cancer J Clin 2005;55:74-108.

How to site this article: Noronha V, Tsomo U, Jamshed A, Hai MA, Wattegama S, Baral RP, et al. A fresh look at oncology facts on south central Asia and SAARC countries. South Asian J Cancer 2012;1:1-4.

\section{News}

A road map to tackle the global challenge of antimicrobial resistance

The Clinical Infectious Diseases Society is organizing a joint meeting "A road map to tackle the global challenge of antimicrobial resistance" on 24 th August 2012 at Chennai from 9 am to $6 \mathrm{pm}$ - with the participation of other medical professional societies in India.

Their aim is to formulate a road map to tackle the Indian perspective of the global antimicrobial resistance problem. As responsible medical societies/ bodies, it is our responsibility to help our Governments in tackling this serious menace, by bringing out a guidelines document. We have also invited international experts (Herman Goossens, Dilip Nathwani, Stephan Harbarth, Arjun Sreenivas, David Paterson, and Paul Thambyah) to discuss about the same as well as plan of action in various continents.

We urge you to actively participate in this meeting and represent the voice of the oncology community.

For registration and further details, please contact Dr. Abdul Ghafur (drghafur@hotmail.com). 